\title{
EP-151
}

\section{Clinical evaluation of procalcitonin level after radiotherapy in cases of hepatobiliary and gastrointestinal malignancies}

\author{
Amar Ranjan SINGH*, Ekta RAHUL
}

Department of Lab Oncology, BRA-IRCH, AlIMS, New Delhi, India

Introduction: Apart from bacterial infections Procalcitonin (PCT) also increases in burns, trauma, and surgery.

Methods: In a prospective study 45 cases (30 male and 15 female) of hepatobiliary and gastrointestinal cancer were taken, which were undergone surgery. It included the cases without (34) and with (11) prior radiotherapy. TPO and PCT were measured (ELISA) on day-1 preoperatively and day-3 (D3) \& 5 (D5) postoperatively.

Results: At base level prior to surgery lower value of TPO was noted in the group not given RT $(174.8 \pm 98.2 \mathrm{pg} / \mathrm{mL})$ than the group who were given $(220.3 \pm 120.7 \mathrm{pg} / \mathrm{mL})$, although statistically insignificant ( $p$-value 0.2$)$. On D3, TPO value in the cases without RT was $287.2 \pm 177.3 \mathrm{pg} / \mathrm{mL}$ and in the cases with RT, it was $472.6 \pm 265.2 \mathrm{pg} / \mathrm{mL}$, was statistically significant ( $p$-value 0.01$)$. On D5, TPO in patients without RT was $409.57 \pm 318.34 \mathrm{pg} / \mathrm{mL}$ (further increased) \& in cases with RT $585.00 \pm 469.61 \mathrm{pg} / \mathrm{mL}$ (further increased), p-value 0.2 , was statistically insignificant. The corresponding PCT preoperatively was $171.6 \pm 563.7 \mathrm{pg} / \mathrm{mL} \mathrm{\&} 100.0 \pm 42.08 \mathrm{pg} / \mathrm{mL}$ in the cases without RT \& with RT respectively (p-value 0.2, statistically insignificant). On D3, PCT value was $668.56 \pm 1,114.09 \mathrm{pg} / \mathrm{mL}$ and $400.63 \pm 660.64 \mathrm{pg} / \mathrm{mL}$ in the cases without \& with RT respectively; $p$-value 0.4 , statistically insignificant. On D5, PCT was 265.54 $\pm 513.77 \& 648.27 \pm 1,771.99 \mathrm{pg} / \mathrm{mL}$ in cases without \& with RT respectively; $p$-value 0.3 , statistically insignificant.

Conclusions: - Higher TPO level after surgery or radiotherapy is indicator of better response. - TPO level may be indicator therapeutic response after radiotherapy or cancer surgery. 